\title{
Contribution of the GSTP1 gene polymorphism to the development of osteosarcoma in a Chinese population
}

\author{
W.R. Qu' ${ }^{1}$, J. Wu ${ }^{2}$ and R. $\mathbf{L i}^{1}$ \\ ${ }^{1}$ Hand \& Foot Surgery and Reparative \& Reconstructive Surgery Center, \\ Orthopaedic Hospital of the Second Hospital of Jilin University, Changchun, \\ China \\ ${ }^{2}$ Department of Orthopaedics, \\ The Affiliated Southeast Hospital of Xiamen University, \\ Orthopaedic Center of People's Liberation Army, Zhangzhou, China \\ Corresponding author: R. Li \\ E-mail: ruililee2@163.com
}

Genet. Mol. Res. 15 (3): gmr.15038034

Received November 9, 2015

Accepted January 15, 2016

Published August 5, 2016

DOI http://dx.doi.org/10.4238/gmr.15038034

Copyright (C) 2016 The Authors. This is an open-access article distributed under the terms of the Creative Commons Attribution ShareAlike (CC BY-SA) 4.0 License.

\begin{abstract}
We conducted a case-control study to investigate the associations between GSTT1, GSTM1, and GSTP1 gene polymorphisms and development of osteosarcoma in a Chinese population. Between January 2013 and February 2015, 153 patients diagnosed with osteosarcoma and 252 control subjects were enrolled in the current study from the Orthopedic Hospital of the Second Hospital of Jilin University. The GSTM1, GSTT1, and GSTP1 gene polymorphisms were detected by polymerase chain reaction coupled with restriction fragment length polymorphism analysis. As determined by a multiple-logistic regression analysis, the Val/Val genotype of GSTP1 was associated with a significantly increased risk of osteosarcoma
\end{abstract}


compared to that of the Ile/Ile genotype, with an odds ratio $(\mathrm{OR})=$ 3.39 , and a $95 \%$ confidence interval $(\mathrm{CI})=1.45-8.13$. Moreover, the $\mathrm{Ile} / \mathrm{Val}+\mathrm{Val} / \mathrm{Val}$ genotype of GSTP1 was correlated with a marginally significant increased risk of osteosarcoma compared to that of the Ile/Ile genotype $(\mathrm{OR}=1.65,95 \% \mathrm{CI}=1.08-2.53)$. However, we did not find any significant associations between the GSTM1 and GSTT1 gene polymorphisms and osteosarcoma risk. In conclusion, our results suggest that the GSTP1 gene polymorphism is associated with an increased risk of osteosarcoma, whereas the GSTM1 and GSTT1 gene polymorphisms may not influence the development of this cancer.

Key words: GSTM1; GSTT1; GSTP1; GSTs; Polymorphism; Osteosarcoma

\section{INTRODUCTION}

Osteosarcoma is the leading cause of bone malignancy in adolescents. The etiology of osteosarcoma is not well understood, and it is reported that many environmental factors including ionizing radiation and a family history of osteosarcoma may contribute to the development of this cancer (Ottaviani and Jaffe, 2009). Previous studies have suggested that many gene polymorphisms may be involved in the development of osteosarcoma, such as those in the angiogenic growth factor genes $V E G F, F G F 2, E R C C 1, E R C C 2$, and GSTs (Zhang et al., 2015a,b; Wang et al., 2015a; Jin et al., 2015; Han et al., 2015; Bian et al., 2015).

Glutathione S transferases (GSTs) comprise a homologous dimer enzyme gene family of detoxifying enzymes that catalyze the conjugation of glutathione with a broad spectrum of endogenous and exogenous compounds. Gene variations in GSTs may alter the expression levels of enzymes and affect their detoxification abilities. Previous studies have reported that the GSTT1, GSTM1, and GSTP1 gene polymorphisms are involved in the development of several kinds of cancers, such as lung cancer, acute lymphoblastic leukemia, breast cancer, skin cancer, head and neck cancer, and oral cancer (Sharma et al., 2015; Guven et al., 2015; Jaramillo-Rangel et al., 2015; Lei et al., 2015; Choudhury et al., 2015; Krüger et al., 2015). Here, we conducted a case-control study to investigate the association between the GSTT1, GSTM1, and GSTP1 gene polymorphisms and development of osteosarcoma in a Chinese population.

\section{MATERIAL AND METHODS}

\section{Subjects}

Between January 2013 and February 2015, 153 patients diagnosed with osteosarcoma from the Orthopedic Hospital of the Second Hospital of Jilin University and the Affiliated Southeast Hospital of Xiamen University were enrolled in the current study. All osteosarcoma diagnoses were confirmed by histopathologic examination. Patients who had primary tumors other than osteosarcoma were excluded. During the same period, 252 subjects were randomly selected from those who obtained a health examination at

Genetics and Molecular Research 15 (3): gmr.15038034 
the Second Hospital of Jilin University and the Affiliated Southeast Hospital of Xiamen University as the control group. Subjects who had a history of cancers were excluded from the study.

The demographic and clinical data from the osteosarcoma patients and control subjects were obtained from their medical records. The demographics included gender, age, smoking status, alcohol use, and familial history of cancer. The clinical data included tumor location and histological subtypes. Written informed consent was obtained from the participants prior to their enrollment in the study. The protocol of this study was previously approved by the Institutional Research Ethics Committee of the Orthopedic Hospital of the Second Hospital of Jilin University.

\section{DNA extraction and genotyping}

Peripheral blood $(5 \mathrm{~mL})$ was obtained from each patient and control subject after enrollment in this study. DNA was extracted from peripheral blood samples using the TIANamp Blood DNA Kit according to manufacturer instruction (Tiangen Biotech, Beijing, China). The GSTM1, GSTT1, and GSTP1 gene polymorphisms were detected by polymerase chain reaction (PCR) coupled with restriction fragment length polymorphism (RFLP) analysis. Primer sequences for GSTM1, GSTT1, and GSTP1 were designed using the Primer Premier v5.0 software (Premier Biosoft International, Palo Alto, CA, USA) (Table 1). The PCR product lengths for GSTM1, GSTT1, and the $\beta$-globin locus were 215, 480, and $268 \mathrm{bp}$, respectively. The product lengths for the GSTP 1 Val allele were 176, 91, and $85 \mathrm{bp}$, and they were 91 and $85 \mathrm{bp}$ for the Val allele.

Table 1. Primers for GSTM1, GSTT1, and GSTP1, and $\beta$-globin locus.

\begin{tabular}{l|l}
\hline Genes & Primers (5'-3') \\
\hline GSTM1 & CTG CCC TAC TTG ATT GAT GGG \\
& CTG GAT TGT AGC AGA TCA TGC \\
\hline GSTT1 & $\begin{array}{l}\text { TTC CTT ACT GGT CCT CAC ATC TC } \\
\text { TCA CCG GAT CAT GGC CAG CA }\end{array}$ \\
\hline GSTP1 & $\begin{array}{l}\text { ACCAGGGCTCTATGGCCAA } \\
\text { TGA CCC GAG AAG AAC GGG T }\end{array}$ \\
\hline$\beta$-globin locus & GAA GAG CCA AGG ACA GGT AC \\
& CAA CTT CAT CCA CGT TCA CC \\
\hline
\end{tabular}

\section{Statistical analysis}

The association between demographic and clinical data and development of osteosarcoma were analyzed using univariate-logistic regression analysis. The HardyWeinberg equilibrium (HWE) was assessed with the goodness-of-fit chi-squared $\left(\chi^{2}\right)$ test. The associations between GSTM1, GSTT1, and GSTP1 gene polymorphisms and risk of osteosarcoma were estimated using multiple-logistic regression analysis, and the results are reported using odds ratios (ORs) and $95 \%$ confidence intervals $(95 \% \mathrm{CIs})$. All statistical analyses were conducted using the SPSS statistical software package, version 17.0 (SPSS Inc., Chicago, IL, USA). All tests were two-sided, with P values less than 0.05 considered as statistically significant. 


\section{RESULTS}

The demographic and clinical characteristics of osteosarcoma patients and control subjects are shown in Table 2. No significant differences were found between osteosarcoma patients and control subjects in terms of gender, smoking status, alcohol use, or familial history of cancer. However, we found that patients with osteosarcoma were significantly younger than the control subjects $(\mathrm{OR}=0.33,95 \% \mathrm{CI}=0.21-0.51)$. Of the 153 samples obtained from patients with osteosarcoma, $86(56.21 \%)$ were of the osteoblastic type, 31 $(20.26 \%)$ were of the chondroblastic type, $26(16.99 \%)$ were of the fibroblastic type, and $10(6.54 \%)$ of other types, $105(68.63 \%)$ were at the extremities, and $48(31.37 \%)$ were at other locations.

Table 2. Demographic and clinical characteristics of osteosarcoma patients and control subjects.

\begin{tabular}{|c|c|c|c|c|c|c|}
\hline Characteristics & Patients $(\mathrm{N}=153)$ & $\%$ & Controls $(\mathrm{N}=252)$ & $\%$ & OR $(95 \% \mathrm{CI})$ & P value \\
\hline \multicolumn{7}{|l|}{ Age (years) } \\
\hline$<20$ & 103 & 67.32 & 102 & 40.48 & 1.0 (Ref.) & \\
\hline$\geq 20$ & 50 & 32.68 & 150 & 59.52 & $0.33(0.21-0.51)$ & $<0.001$ \\
\hline \multicolumn{7}{|l|}{ Gender } \\
\hline Female & 61 & 39.87 & 114 & 45.24 & 1.0 (Ref.) & \\
\hline Male & 92 & 60.13 & 138 & 54.76 & $1.25(0.81-1.91)$ & 0.29 \\
\hline \multicolumn{7}{|l|}{ Smoking status } \\
\hline No & 128 & 83.66 & 218 & 86.51 & 1.0 (Ref.) & \\
\hline Yes & 25 & 16.34 & 34 & 13.49 & $1.25(0.68-2.27)$ & 0.43 \\
\hline \multicolumn{7}{|l|}{ Alcoholuse } \\
\hline No & 123 & 80.39 & 219 & 86.90 & 1.0 (Ref.) & \\
\hline Yes & 30 & 19.61 & 33 & 13.10 & $1.62(0.91-2.88)$ & 0.08 \\
\hline \multicolumn{7}{|c|}{ Family history of cancer } \\
\hline No & 134 & 87.58 & 235 & 93.25 & 1.0 (Ref.) & \\
\hline Yes & 19 & 12.42 & 17 & 6.75 & $1.96(0.93-4.16)$ & 0.05 \\
\hline \multicolumn{7}{|c|}{ Histological subtype } \\
\hline Osteoblastic & 86 & 56.21 & & & & \\
\hline Chondroblastic & 31 & 20.26 & & & & \\
\hline Fibroblastic & 26 & 16.99 & & & & \\
\hline Others & 10 & 6.54 & & & & \\
\hline \multicolumn{7}{|l|}{ Tumor location } \\
\hline Extremities & 105 & 68.63 & & & & \\
\hline Others & 48 & 31.37 & & & & \\
\hline
\end{tabular}

The genotype frequencies of GSTM1, GSTT1, and GSTP1 genes are shown in Table 3. As determined by $\chi^{2}$ test, a significant difference in the frequency of GSTP 1 was found between osteosarcoma patients and control subjects $\left(\chi^{2}=10.77, \mathrm{P}=0.01\right)$. However, no significant differences were found in the frequencies of GSTM1 $\left(\chi^{2}=10.77, \mathrm{P}=0.01\right)$ or GSTT1 $\left(\chi^{2}=10.77, \mathrm{P}=0.01\right)$ between patients and controls. As determined by a multiplelogistic regression analysis, the Val/Val genotype of GSTP 1 was associated with a significantly increased risk of osteosarcoma compared to that of the Ile/Ile genotype $(\mathrm{OR}=3.39,95 \% \mathrm{CI}=$ 1.45-8.13). Moreover, the IIe/Val+Val/Val genotype of GSTP1 was correlated with a marginally significant increased risk of osteosarcoma compared to that of the Ile/Ile genotype $(\mathrm{OR}=$ $1.65,95 \% \mathrm{CI}=1.08-2.53)$. However, we did not find any significant associations between the GSTM1 and GSTT1 gene polymorphisms and osteosarcoma risk. 
Table 3. Association between GSTM1, GSTT1, and GSTP1 gene polymorphisms and risk of osteosarcoma.

\begin{tabular}{l|c|c|c|c|c|c|c|c}
\hline Gene & Patients & $\%$ & Controls & $\%$ & $\chi^{2}$ test & P value & OR $(95 \% \mathrm{CI})^{1}$ & P value \\
\hline GSTM1 & & & & & & & & \\
\hline Present & 88 & 57.52 & 157 & 62.30 & & & 1.0 (Ref.) & \\
\hline Null & 65 & 42.48 & 95 & 37.70 & 0.91 & 0.34 & $1.22(0.79-1.88)$ & 0.34 \\
\hline GSTT1 & & & & & & & & \\
\hline Present & 85 & 55.56 & 145 & 57.54 & & & 1.0 (Ref.) & \\
\hline Null & 68 & 44.44 & 107 & 42.46 & 0.15 & 0.70 & $1.08(0.71-1.66)$ & 0.70 \\
\hline GSTP1 & & & & & & & & \\
\hline IIe/IIe & 64 & 41.17 & 135 & 53.57 & & & $1.0($ Ref. $)$ & \\
\hline IIe/Val & 71 & 46.41 & 105 & 41.67 & & & $1.45(0.93-2.27)$ & 0.09 \\
\hline Val/Val & 19 & 12.42 & 12 & 4.76 & 10.77 & 0.01 & $3.39(1.45-8.13)$ & 0.002 \\
\hline IIe/Val+Val/Val & 90 & 58.82 & 117 & 46.43 & & & $1.65(1.08-2.53)$ & 0.02 \\
\hline
\end{tabular}

${ }^{1}$ Adjusted for gender, age, smoking, drinking, and familial history of cancer.

\section{DISCUSSION}

In the current study, we investigated whether the GSTM1, GSTT1, and GSTP1 gene polymorphisms influenced the development of osteosarcoma in a Chinese population, and found that the GSTP1 gene polymorphism did indeed affect osteosarcoma susceptibility.

Previous studies have reported on the correlation between the GSTP1 gene polymorphism and several kinds of cancers, such as lung cancer, acute lymphoblastic leukemia, breast cancer, skin cancer, head and neck cancer, and oral cancer (Choudhury et al., 2015; Guven et al., 2015; Jaramillo-Rangel et al., 2015; Krüger et al., 2015; Lei et al., 2015; Sharma et al., 2015). For example, Sharma et al. (2015) conducted a study in an Indian population, and reported that the null GSTT1 and wild-type GSTP1 genotypes were associated with an increased risk of lung cancer. However, Guven et al. (2015) suggested that the GST variants might not influence the risk of developing childhood acute lymphoblastic leukemia in a Turkish population. Furthermore, Jaramillo-Rangel et al. (2015) reported that the GSTM1null genotype was associated with breast cancer risk in a Mexican population. Lei et al. (2015) demonstrated that the GSTP1 105Val polymorphism might contribute to the development of skin cancer in a Chinese population. Choudhury et al. (2015) reported that the GSTM1-null genotypes were associated with head and neck cancer susceptibility in an Indian population. Lastly, Krüger et al. (2015) reported that the GSTMI deletion could help to identify German patients at risk for oral cancer development.

For the reported association between GST gene polymorphisms and the development and prognosis of osteosarcoma (Li et al., 2014), two meta-analyses have further evaluated their correlations (Wang et al., 2015b; Han et al., 2015). Specifically, Li et al. (2014) reported that the GG genotype of GSTP1 was significantly associated with overall survival of osteosarcoma in a Chinese population. Wang et al. (2015b) conducted a meta-analysis of six case-control studies, and did not find any association between GSTT1 polymorphisms and osteosarcoma risk. However, Han et al. (2015) performed a pooled meta-analysis of three case-control studies, and their results revealed a significant association between the GSTT1-null genotype and risk of developing osteosarcoma. The results herein indicate that the GSTP1 gene polymorphism may affect osteosarcoma susceptibility in a Chinese population. The discrepancies between these different studies may be due to different study populations, sample sizes, and/or selection criteria for patients and controls.

In conclusion, the results of the current study indicate that the GSTP1 gene

Genetics and Molecular Research 15 (3): gmr.15038034 
polymorphism is associated with an increased risk of osteosarcoma. Further studies are needed to elucidate the impact of GST gene polymorphisms in the risk of osteosarcoma.

\section{Conflicts of interest}

The authors declare no conflict of interest.

\section{ACKNOWLEDGMENTS}

We thank the great help from staffs in the Second Hospital of Jilin University and the Affiliated Southeast Hospital of Xiamen University for collecting blood samples from the study subjects.

\section{REFERENCES}

Bian Z, He Q, Wang X, Li M, et al. (2015). Association of genetic polymorphisms with osteosarcoma risk: a metaanalysis. Int. J. Clin. Exp. Med. 8: 8317-8328.

Choudhury JH, Singh SA, Kundu S, Choudhury B, et al. (2015). Tobacco carcinogen-metabolizing genes CYP1A1, GSTM1, and GSTT1 polymorphisms and their interaction with tobacco exposure influence the risk of head and neck cancer in Northeast Indian population. Tumour Biol. 36: 5773-5783. http://dx.doi.org/10.1007/s13277-015-3246-0

Guven M, Unal S, Erhan D, Ozdemir N, et al. (2015). Role of glutathione S-transferase M1, T1 and P1 gene polymorphisms in childhood acute lymphoblastic leukemia susceptibility in a Turkish population. Meta Gene 5: 115-119. http:// dx.doi.org/10.1016/j.mgene.2015.06.002

Han J, Deng W, Wang L and Qi W (2015). Null genotypes of glutathione S-transferase $\mathrm{m} 1$ and glutathione S-transferase q1 are associated with osteosarcoma risk: A meta-analysis. Oncol. Lett. 9: 1912-1916.

Jaramillo-Rangel G, Ortega-Martínez M, Cerda-Flores RM and Barrera-Saldaña HA (2015). Polymorphisms in GSTM1, GSTT1, GSTP1, and GSTM3 genes and breast cancer risk in northeastern Mexico. Genet. Mol. Res. 14: 6465-6471. http://dx.doi.org/10.4238/2015.June.11.22

Jin G, Wang M, Chen W, Shi W, et al. (2015). Single nucleotide polymorphisms of nucleotide excision repair and homologous recombination repair pathways and their role in the risk of osteosarcoma. Pak. J. Med. Sci. 31:269-273.

Krüger M, Pabst AM, Mahmoodi B, Becker B, et al. (2015). The impact of GSTM1/GSTT1 polymorphism for the risk of oral cancer. Clin. Oral Investig. 19: 1791-1797. http://dx.doi.org/10.1007/s00784-015-1400-0

Lei Z, Liu T, Li X, Xu X, et al. (2015). Contribution of glutathione S-transferase gene polymorphisms to development of skin cancer. Int. J. Clin. Exp. Med. 8: 377-386.

Li JZ, Tian ZQ, Jiang SN and Feng T (2014). Effect of variation of ABCB1 and GSTP1 on osteosarcoma survival after chemotherapy. Genet. Mol. Res. 13: 3186-3192. http://dx.doi.org/10.4238/2014.April.25.3

Ottaviani G and Jaffe N (2009). The epidemiology of osteosarcoma. Cancer Treat. Res. 152: 3-13. http://dx.doi. org/10.1007/978-1-4419-0284-9_1

Sharma N, Singh A, Singh N, Behera D, et al. (2015). Genetic polymorphisms in GSTM1, GSTT1 and GSTP1 genes and risk of lung cancer in a North Indian population. Cancer Epidemiol. 39: 947-955. http://dx.doi.org/10.1016/j. canep.2015.10.014

Wang J, Liu H, Liu X and Qi X (2015a). Effect of variation of FGF2 genotypes on the risk of osteosarcoma susceptibly: a case control study. Int. J. Clin. Exp. Med. 8: 6114-6118.

Wang Z, Xu H, He M, Wu H, et al. (2015b). The association of glutathione S-transferase polymorphisms in patients with osteosarcoma: evidence from a meta-analysis. Eur. J. Cancer Care (Engl.) 24: 417-424. http://dx.doi.org/10.1111/ ecc. 12197

Zhang G, Bai R, Zhang T, Zhang H, et al. (2015a). Investigation of the role of VEGF gene polymorphisms in the risk of osteosarcoma. Genet. Mol. Res. 14: 8283-8289. http://dx.doi.org/10.4238/2015.July.27.16

Zhang HF, Yan JP, Zhuang YS and Han GQ (2015b). Association between angiogenic growth factor genetic polymorphisms and the risk of osteosarcoma. Genet. Mol. Res. 14: 10524-10529.http://dx.doi.org/10.4238/2015.September.8.14

Genetics and Molecular Research 15 (3): gmr.15038034 